\title{
Arginine Vasopressin and Arginine Vasotocin Inhibit Ovine Fetal/Maternal Water Transfer
}

\author{
ROSEMARY D. LEAKE, ${ }^{(9)}$ HENDRIK STEGNER, SUE M. PALMER, GARY K. OAKES, AND \\ DELBERT A. FISHER WITH THE TECHNICAL ASSISTANCE OF SUSAN EVERETT \\ Departments of Pediatrics and Obstetrics, UCLA School of Medicine, Harbor/UCLA Medical Center, \\ Torrance, California
}

\begin{abstract}
Summary
After the infusion of $500 \mathrm{ml} 20 \%$ mannitol to 12 pregnant ewes, we studied maternal and fetal plasma osmolality and maternal hematocrit responses and monitored blood pressure, heart rate, blood gas, and pH in chronically catheterized fetal lambs at 129140 days gestation. To examine the effect of arginine vasotocin (AVT) and arginine vasopressin (AVP) on fetal/maternal water transfer, the mannitol infusion was repeated 1 day before or after the baseline mannitol study during a 2-h fetal infusion of AVT (7 $\left.\mu \mathrm{U} \cdot \mathrm{kg}^{-1} \cdot \mathrm{min}^{-1}\right)$ or AVP $\left(20-400 \mu \mathrm{U} \cdot \mathrm{kg}^{-1} \cdot \mathrm{min}^{-1}\right)$ in eight and five animals, respectively. Mannitol was administered to the ewe after $1 \mathrm{~h}$ of the 2-h AVT or AVP infusion. The fetal and maternal osmolality and hematocrit responses were compared to the baseline mannitol responses in the same sheep. Maternal and fetal blood gases and pH were measured throughout the study periods during the AVT studies. In four of the ewes, an identical (sham) study was performed substituting $500 \mathrm{ml}$ normal saline for the mannitol infusion to the ewe.

Fetal AVP infusion alone produced a significant decrease in fetal plasma osmolality $(P<0.001 ;$ two-way analysis of variance) and a slight increase in maternal osmolality $(P<0.05)$. Fetal AVP or AVT infusion significantly obtunded the fetal osmolality increment induced by maternal mannitol (each $P<0.001$ ); moreover, there was a greater decrease in maternal hematocrit after mannitol alone than after mannitol with AVT $(P<0.05)$. Fetal hematocrit was maintained unchanged by transfusion with heparinized maternal blood. Maternal and fetal heart rates and maternal blood pressure remained unchanged during the studies. But during the fetal AVT infusion, fetal blood pressure increased from $64 \pm 3$ to $75 \pm 2 \mathrm{mmHg}(P<0.01)$; fetal and maternal $\mathrm{Po}_{2}$ and $\mathrm{pH}$ remain unchanged; and fetal $\mathrm{PCO}_{2}$ increased from $30 \pm 2$ to $37 \pm 4(P<$ 0.05 ). Normal saline (sham protocol) produced no change in any parameter.

The data indicate that fetal blood levels of AVP and AVT can influence transplacental water flow. Fetal AVP infusion produces a net gain in fetal water by inhibiting baseline fetal to maternal water flow. Both AVP and AVT infusion inhibit fetal to maternal water transfer after an osmotic stimulus to the ewe.
\end{abstract}

\section{Abbreviations}

AVP, arginine vasopressin

AVT, arginine vasotocin

Examination of fetal to maternal water exchange is possible by applying an acute osmotic stimulus (hypertonic saline or mannitol) to the maternal circulation. This creates a transplacental osmotic gradient and evokes a shift in water from the fetal to the maternal circulation $(1,2)$. The magnitude of this fetal to maternal water transfer reflects, indirectly, the permeability of the placental membranes under conditions in which placental blood flow is not limiting. The resultant water flux can be measured by a change in concentration of fetal and maternal vascular volume markers, including hematocrit and osmolality. If an identical osmotic stimulus is repeated during AVP or AVT infusion into the fetal circulation, any effect of the exogenous hormone on placental water flow will be reflected in a diminished or augmented fetal to maternal water flux.

Using a modification of the technique developed by Faber and Green (3), we previously infused hypertonic saline into the pregnant ewe as a means of producing a net flux of water from the fetal to the maternal compartment (4). With this model we demonstrated that the acute fetal water loss evokes vigorous fetal AVP secretion. In the present study we employed the model to study the effect of fetal AVP or AVT on placental water flow. We modified the protocol to substitute mannitol (which does not cross the placenta) for the maternal osmolar load and assessed placental water flux before and during the infusion of AVP or AVT to the fetus.

\section{MATERIALS AND METHODS}

Femoral venous and arterial catheters were inserted under local anesthesia into date-bred healthy (Columbia-Suffolk) ewes with singleton fetuses of 124-129 days gestation. A maternal hysterotomy was conducted under ketamine anesthesia. The fetal hind limb was exteriorized and catheters were inserted into the dorsal vein and artery and advanced to the site of maximal circulation. The fetus was then replaced in the uterus, the fetal catheters were exteriorized to a pouch attached to the flank of the ewe, and the uterus and maternal abdominal wall were closed. Catheters were maintained patent with a dilute heparin solution.

Chloramphenicol was given intravenously for 5 days to the ewe and fetus and injected into the amniotic fluid for 5 days postoperatively. Animals were maintained in indoor pens and had ad libitum access to baled alfalfa and water. Six to seven days were allowed for surgical recovery. Gestational age at the time of the studies ranged from 130-140 days.

On the day of study, drinking water was removed from the cage. Studies were conducted only if the fetal $\mathrm{pH}$ exceeded 7.35. With the ewe standing, maternal and fetal blood pressure were measured continuously by means of a Statham P23 transducer positioned at the ewe's midabdomen, and maternal and fetal heart rates were recorded at 10 -min intervals using a Beckman Offner 8 channel direct writing recorder. Fetal pressures were corrected for amniotic fluid pressure. Fifty milliliters whole blood were removed from the maternal circulation into a heparinized syringe (1 unit heparin/4 cc blood) for subsequent fetal replacement transfusion.

Two study protocols were utilized. In Protocol I (mannitol control), three baseline blood samples $(4 \mathrm{ml}$ each) were obtained at 10 -min intervals from the femoral arterial catheter of 12 ewes and the dorsal arterial catheter of their fetuses for plasma osmolality and hematocrit measurements. Maternal and fetal $\mathrm{pH}, \mathrm{Po}_{2}$, and $\mathrm{PCO}_{2}$ were measured at the time of each blood sampling. All samples were collected only after a sample of blood equivalent to 
the $4 \mathrm{ml}$ dead space in the catheter was withdrawn. After the baseline blood samples were obtained, $500 \mathrm{ml}$ mannitol [Osmitrol (20\% solution), Travenol Laboratories, Inc., Deerfield, IL] were infused via the maternal femoral venous catheter over $10 \mathrm{~min}$. Beginning $10 \mathrm{~min}$ after the start of the mannitol infusion, five (4 ml each) blood samples were obtained from the maternal and fetal arterial catheters at 10 -min intervals. Each sample was replaced with an equivolemic quantity of isotonic saline to the ewe and an equivolemic transfusion of maternal heparinized whole blood to the fetus.

One day before and one day later, Protocol II (Mannitol + AVP or AVT) was performed (once using AVT and once AVP) in the same animals. After obtaining three baseline blood samples at 10 -min intervals, AVP $\left(20-400 \mu \mathrm{U} \cdot \mathrm{kg}^{-1} \cdot \mathrm{min}^{-1}\right)$ or AVT $(7 \mu \mathrm{U}$. $\mathrm{kg}^{-1} \cdot \mathrm{min}^{-1}$ ) was infused for $2 \mathrm{~h}$ into the fetal dorsal venous catheter of five and eight animals, respectively. The infusion rates varied among animals but in any individual fetus the rate was maintained constant. Blood samples $(4 \mathrm{ml}$ from the fetus and $5 \mathrm{ml}$ from the ewe) were obtained every $10 \mathrm{~min}$ from both the fetus and ewe throughout the AVP or AVT infusion period. Maternal and fetal samples were replaced with saline and maternal blood, respectively, as described. At the completion of the first $60 \mathrm{~min}$ of the fetal AVP or AVT infusion, mannitol was infused into the mother ewe via the femoral venous catheter in a manner identical to that of Protocol I.

In four of the study animals, an additional (sham) study was performed one day before or subsequent to Protocol I and II studies. In the sham protocol identical blood sampling was conducted in the fetus and ewe during and after a $500-\mathrm{ml}$ infusion of isotonic saline infusion given to the ewe over $1 \mathrm{~h}$. Maternal and fetal blood pressure, heart rate, blood gases and $\mathrm{pH}$, serum osmolality and hematocrit were measured similarly to protocols I and II.

Four-milliliter samples of whole blood were collected in iced tubes containing $15 \%$ EDTA. All samples were spun at $2000 \mathrm{rpm}$ in a refrigerated centrifuge and the plasma separated. One-milliliter plasma samples were stored at $-20^{\circ} \mathrm{C}$ for measurement of osmolality concentrations. AVP concentrations were measured in the plasma and infusate solutions by radioimmunoassy (5). Blood hematocrit was measured in duplicate. Plasma osmolality was determined by freezing point depression using an Advanced Instruments $3 R$ precision osmometer.

Each protocol was analyzed as a single, independent experiment. Mean values for the baseline and poststimulation (postmannitol) study periods were compared using the paired $t$ test. Comparisons between groups for Protocol I, Protocol II, and sham studies were made by two-way analysis of variance (ANOVA). Values were expressed as means \pm standard error of the mean.

\section{RESULTS}

Normal saline infusion into the ewe (sham protocol) produced no change in heart rate, blood pressure, or blood gases. Maternal serum hematocrit remained unchanged during the sham procedures and there was no change in fetal plasma osmolality (baseline, $286 \pm 1.8 \mathrm{mOsm} / \mathrm{kg}$ versus postsaline, $285 \pm 2.2 \mathrm{mOsm} / \mathrm{kg}$ ). The mean osmolality levels for the sham protocol, mannitol alone,

Table 1. Mean ( \pm S.E.M.) fetal plasma osmolalities during various study periods

\begin{tabular}{lcccc}
\hline & Baseline & $\begin{array}{c}\text { Posthor- } \\
\text { mone infu- } \\
\text { sion }\end{array}$ & Postsaline & $\begin{array}{c}\text { Postmanni- } \\
\text { tol }\end{array}$ \\
\hline $\begin{array}{l}\text { Sham protocol } \\
\text { Mannitol }\end{array}$ & $286 \pm 1.8$ & & $285 \pm 2.2$ & \\
$\begin{array}{l}\text { AVP + man- } \\
\text { nitol }\end{array}$ & $292 \pm 2.1$ & & & $306 \pm 4.1$ \\
AVT + man- & $289 \pm 3.6$ & $283 \pm 3.6$ & & $292 \pm 4.0$ \\
$\quad$ nitol & & $292 \pm 3.4$ & & $298 \pm 3.0$ \\
\hline
\end{tabular}

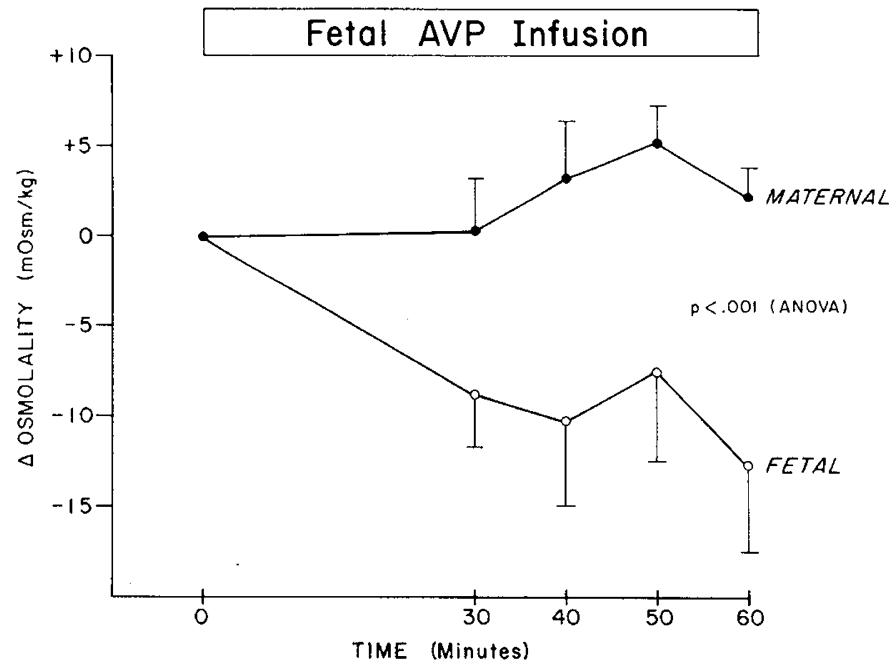

Fig. 1. Mean ( \pm S.E.M.) plasma osmolality changes during AVP infusion in five fetuses. Overall differences $=P<0.01$; ANOVA.

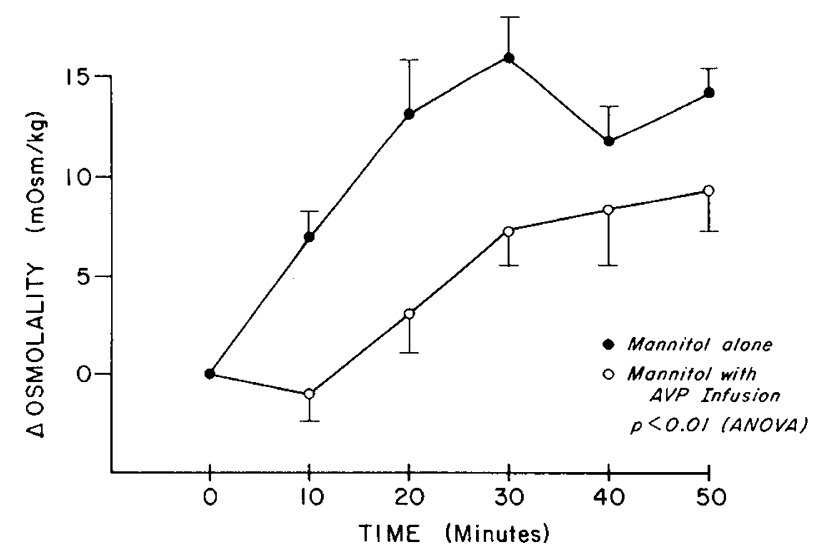

Fig. 2. Mean fetal osmolal changes after mannitol infusion to the ewe.

mannitol + AVP, and mannitol + AVT̄ studies are listed in Table 1 .

Mannitol versus Mannitol $+A V P$. The mean ( \pm S.E.M.) basal fetal plasma AVP level was $0.7 \pm 0.1 \mu \mathrm{U} / \mathrm{ml}$ and the maternal baseline level was $0.5 \pm 0.1 \mu \mathrm{U} / \mathrm{ml}$. The mean steady state fetal AVP level at the completion of the $60 \mathrm{~min}$ of AVP infusion was $13.2 \pm 2.6 \mu \mathrm{U} / \mathrm{ml}$; however, steady state levels varied in the several fetuses from $1.8-32 \mu \mathrm{U} / \mathrm{ml}$ because of the varying amounts of AVP infused $\left(20-400 \mu \mathrm{U} \cdot \mathrm{min}^{-1} \cdot \mathrm{kg}^{-1}\right)$. All of the values were in the physiologic range observed in mild-severe dehydration.

Figure 1 shows the changes in fetal and maternal plasma osmolality in response to the 1-h fetal AVP infusion, before maternal mannitol infusion. The mean ( \pm S.E.M.) fetal baseline osmolality was $293 \pm 3.6 \mathrm{mOsm} / \mathrm{kg}$ and the mean maternal baseline osmolality was $297 \pm 1.7 \mathrm{mOsm} / \mathrm{kg}$ (not significant). Over the 1-h AVP infusion, mean fetal osmolality decreased 9.9 $\pm 1.9 \mathrm{mOsm} / \mathrm{kg}(P<0.001)$ and maternal osmolality increased 2.5 $\pm 1.1 \mathrm{mOsm} / \mathrm{kg}(P<0.05)$.

Figure 2 shows the fetal plasma osmolality responses to maternal mannitol infusion with and without AVP infusion. Without AVP infusion fetal osmolality increased significantly by $10 \mathrm{~min}$, whereas the response was delayed and obtunded in the fetuses infused with AVP $(+7.0 \pm 2.1$ versus $-1.0 \pm 2.8 \mathrm{mOsm} / \mathrm{kg}, P<$ $0.01)$. Fetal plasma osmolality increased gradually throughout a 40-min period in both groups. The mean increments over baseline fetal values in the mannitol alone and mannitol + AVP fetuses at $50 \mathrm{~min}$ were $14.2 \pm 2.1$ and $9.3 \pm 3.6 \mathrm{mOsm} / \mathrm{kg}$, respectively $(P$ $<0.05$ ); moreover, the areas under the response curves for the two groups were significantly different by ANOVA $(P<0.001)$. Fetal 
hematocrit did not change significantly in either group of animals probably because of the blood replacement.

Figure 3 shows the changes in maternal plasma osmolality after mannitol infusion in the two study protocols. Values increased

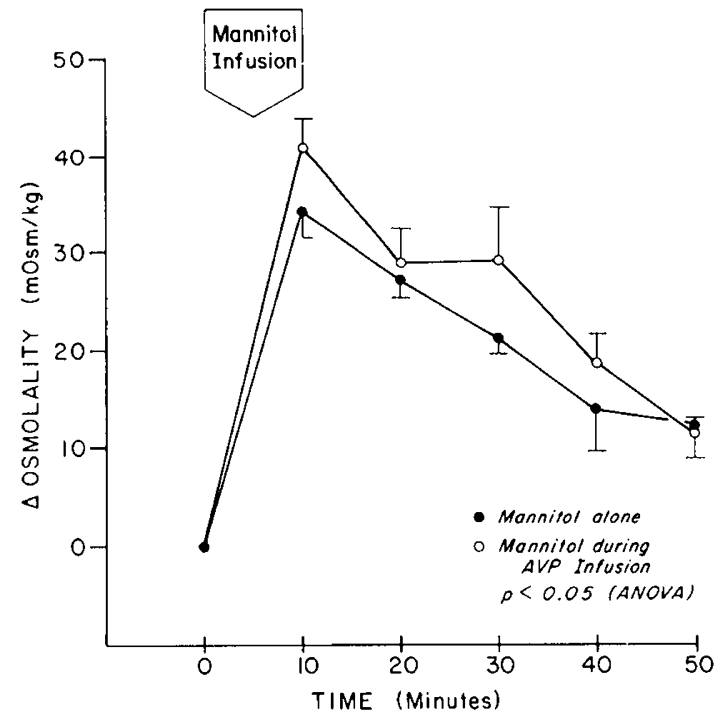

F 5. 3. Maternal osmolal changes after mannitol infusion to the ewe. markedly in both the mannitol alone and mannitol + fetal AVP infusion groups. The peak increment (at $10 \mathrm{~min}$ ) was greater with fetal AVP infusion than without $(41.0 \pm 2.9$ versus $34.4 \pm 3.0$ $\mathrm{mOsm} / \mathrm{kg}$ ). The areas under the mean response curve also were greater in ewes whose fetuses received AVP infusions $(P<0.05)$.

Mannitol versus Mannitol $+A V T$. Figure 4 shows the fetal blood pressure and heart rate responses during the AVT infusion (Protocol II). Each value represents the mean ( \pm S.E.M.) of the samples obtained every $10 \mathrm{~min}$ during the baseline period, the initial hour of fetal AVT infusion, and the postmannitol period. Fetal heart rate changes were variable in the study animals. Fetal blood pressure increased from $64 \pm 3$ to $75 \pm 2$ torr $(P<0.01)$. Fetal and maternal $\mathrm{PO}_{2}$ and $\mathrm{pH}$ remained unchanged and fetal $\mathrm{PCO}_{2}$ increased from $30 \pm 2$ to $37 \pm 4(P<0.05)$.

There was a greater decrease in maternal hematocrit (baseline to postmannitol) after mannitol alone that during mannitol with fetal AVT infusion $(34.4 \pm 1.0$ to $27.7 \pm 1.6$ versus $29.7 \pm 2.3$ to $26.0 \pm 1.9 \% \Delta 6.7$ versus $3.7 ; P<0.05$ )

Figure 5 shows the fetal plasma osmolality responses to maternal mannitol infusion alone and mannitol + fetal AVT infusion. Fetal AVT infusion alone produced no change in fetal osmolality (baseline, $289 \pm 3.0$ versus AVT, $292 \pm 3.4 \mathrm{mOsm} / \mathrm{kg}$ ). Maternal mannitol infused without fetal AVT evoked a greater peak increment (at $20 \mathrm{~min})$ in fetal osmolality $(25 \pm 5.0 \mathrm{mOsm} / \mathrm{kg})$ than did maternal mannitol during fetal AVT infusion $(7 \pm 3.5 \mathrm{mOsm} / \mathrm{kg})$. The area under the mean response curves also was greater in ewes whose fetuses received AVT infusions $(P<0.01)$.
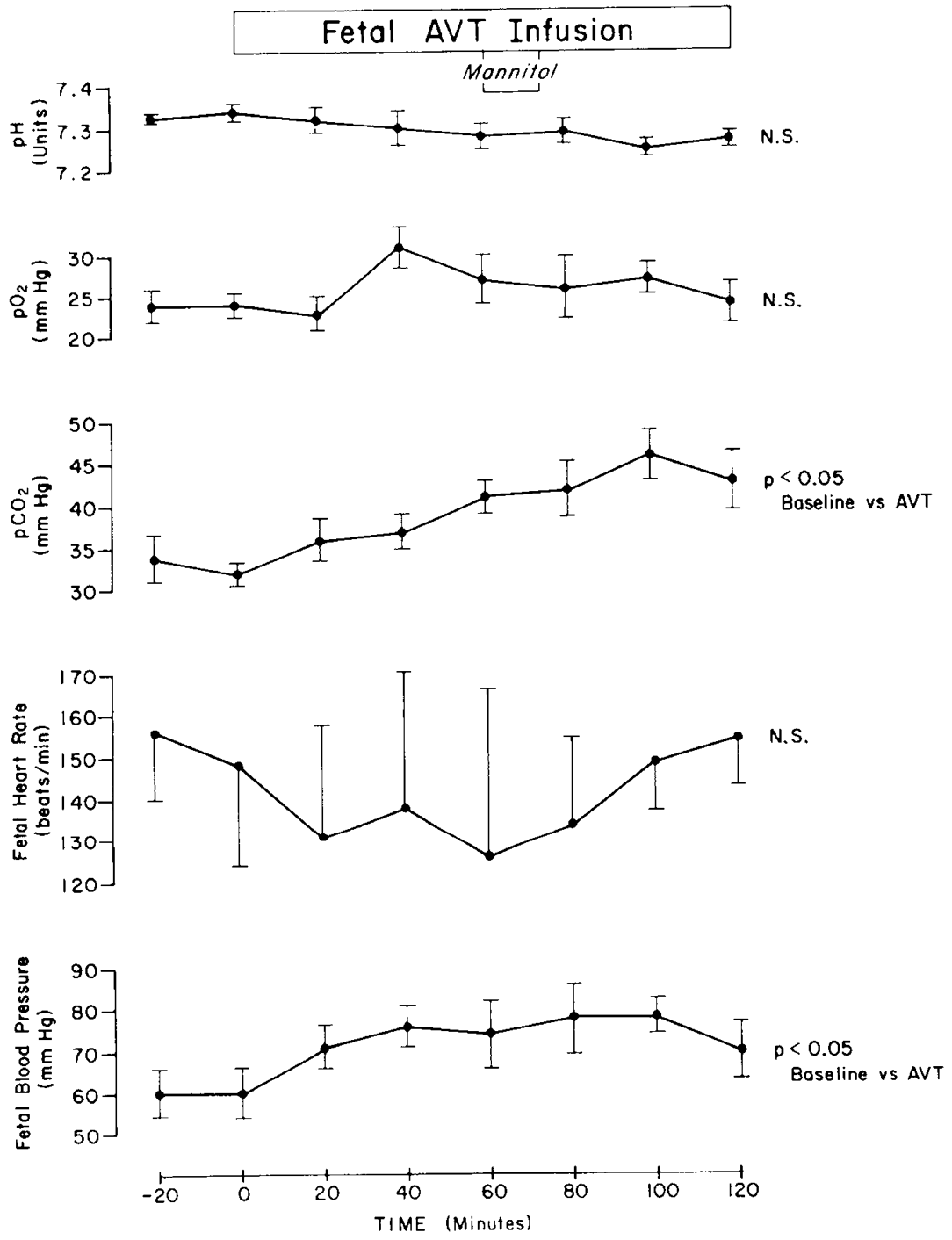

Fig. 4. Fetal $\mathrm{pH}, \mathrm{PO}_{2}, \mathrm{PcO}_{2}$, heart rate, and blood pressure during fetal AVT infusion. 


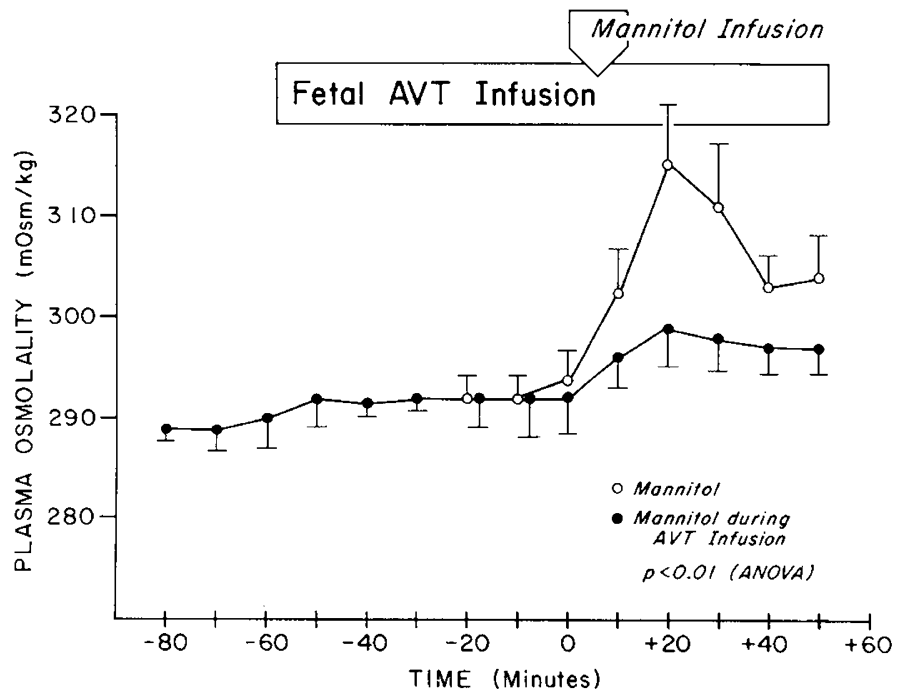

Fig. 5. Fetal osmolality after mannitol infusion to the ewe.

Flow across the placental membranes equals the filtration coefficient times change in pressure, where the filtration coefficient is $1 /$ resistence. Because we observed a significant increase in fetal blood pressure during the infusion of $7 \mu \mathrm{U} \cdot \mathrm{kg}^{-1} \cdot \mathrm{min}^{-1}$ AVT, we repeated the studies in two animals at a reduced AVT concentration producing no significant change in fetal blood pressure. There was a corresponding decrease in the effect on placental water transfer at the lesser concentration of AVT. The lowest concentration infused continued to show an effect, however, in the absence of any biophysical changes, suggesting that the site of the effect of AVP and AVT may be on placental pore size.

\section{DISCUSSION}

The present results show a clear effect of fetal plasma AVP on fetal-maternal water flux across the ovine placenta. AVP infusion significantly reduced fetal plasma osmolality over a 60 -min period indicating an increase in fetal total body water (Fig. 1). This would seem most likely due to an alteration of transplacental water fluxes, e.g., inhibition of fetal to maternal water flux relative to maternal to fetal flux. The mechanism, however, is not clear, and fetal AVT infusion (Fig. 5) did not reduce fetal plasma osmolality. Inhibition of renal free water clearance might have contributed: Robillard et al. (6) have shown an effect of AVP on free water clearance in the third trimester sheep.

In addition, the fetal AVP infusion at least partially blocked the fetal to maternal water transfer induced by maternal mannitol infusion. This is demonstrated by the highly significant reduction in the areas under the postmannitol plasma osmolality increment versus time curves for the AVP infused versus non-AVP control fetuses (Fig. 2) and the significant increase in the postmannitol osmolality increment versus time curve for the ewes of the AVP infused versus control ewes (Fig. 3). A similar effect was produced by fetal AVT infusion (Fig. 5).

It is unlikely that the magnitude of osmotic change after mannitol produced by the addition of AVP or AVT represents a change in hydrostatic pressure alone. Our findings of a change in water flow between the fetal and maternal circulations might be explained by a change in placental blood flow. This seems unlikely because of the results of the studies of Iwamoto, et al. (7) who measured the hemodynamic effects of vasopressin infusion in the chronically catheterized fetal lamb. The AVP infusions in that study produced plasma AVP levels $(6.8-36.4 \mathrm{mU} / \mathrm{ml})$ comparable to those achieved in our study (mean \pm S.E.M. $=13.2 \pm 2.6 \mathrm{mU} /$ $\mathrm{ml}$ ) and produced a slight decrease in fetal plasma osmolality. In addition, these investigators observed an increase (of nearly 10\%) in the $\%$ of fetal cardiac output delivered to the umbilical placental circulation and a significant increase in umbilical placental resistence. Measured flow rates to the placenta did not change in a consistent fashion. This was felt to be secondary to the opposing effects of fetal bradycardia (producing decreased placental blood flow) and increased blood pressure (producing increased placental flow). Blood flow to the kidneys was not altered.

Vizsolyi and Perks (8) have shown that AVP or AVT added to the fetal side of the isolated guinea pig amnion diminishes fetal to maternal water flux in response to hyperosmolal conditions on the maternal side. We investigated a possible role of AVT in placental water transfer. As indicated, a significant effect was observed.

These studies document for the first time that AVP or AVT in the ovine fetal circulation diminishes fetal/maternal water transfer. The mechanism for this effect is not clear. AVT may change fetal/placental blood flow or may have a direct effect on membrane pore size. The latter hypothesis is supported by the report that AVP or AVT decrease osmolar induced water transfer from the fetal to the maternal side of the isolated guinea pig amnion in vitro when AVP or AVT are added to the fetal side of the membranes (8). Effects in this model must be due to membrane flow changes. In addition, we found the diminution of fetal to maternal water transfer to occur in the absence of cardiovascular changes (heart rate, blood pressure) in several of our study animals.

\section{REFERENCES AND NOTES}

1. Battaglia, F., Prystowsky, H., Smisson, C., Hellegers, A., and Bruns, P.: The effect of the administration of fluids intravenously to mothers upon the concentrations of water and electrolytes in plasma of human fetuses. Pediatrics 25: 2 (1960)

2. Bruns, P. D., Linder, R. O., Drose, V. E., and Battaglia, F.: The placental transfer of water from fetus to mother following the intravenous infusion of hypertonic mannitol to the maternal rabbit. Am. J. Obstet. Gynecol., 86: 160 (1963).

3. Faber, J. J. and Green, T. J.: Foetal placental blood flow in the lamb. J. Physiol, 223: 375 (1972).

4. Leake, R. D., Weitzman, R. E., Effros, R. M., Siegel, S. R., and Fisher, D. A. Maternal osmolar homeostasis: fetal posterior pituitary autonomy. Pediatr. Res., 13: 841 (1979).

5. Skowsky, W. R., Rosenbloom, A. A., and Fisher, D. A.: Radioimmunoassay of arginine vasopressin, development and application. J. Clin. Endocrinol. Metab. 38: 278 (1974)

6. Robillard, J. E., Weitzman, R. E., Brumeister, L., and Smith, F. G., Jr.: Developmental aspects of the renal response to hypoxia in the lamb fetus. Circul. Res., 48: 128 (1981).

7. Iwamoto, H. S., Rudolph, A. M., Keil, L. C., and Heymann, M. A.: Hemodynamic responses of the sheep fetus to vasopressin infusion. Circ. Res., 44: 430 (1979).

8. Vizsolyi, E. and Perks, A. M.: The effect of arginine vasotocin on the isolated amniotic membrane of the guinea pig. Can. J. Zool., 52: 371 (1974).

9. Requests for reprints should be addressed to: Dr. Rosemary D. Leake, Department of Pediatrics, Harbor/UCLA Medical Center, 1000 West Carson Street, Torrance, California 90509.

10. Supported by United States Public Health Service Grant \#HD 06335 from the National Institute of Child Health and Human Development

11. Received for publication June 8, 1982.

12. Accepted for publication November $21,1982$. 